\title{
Workshops on photonics and optoinformatics for school students at ITMO University
}

Natalia Andreeva, Azat Ismagilov, Tatiana Kuzmina, Sergei Kozlov

Natalia Andreeva, Azat Ismagilov, Tatiana Kuzmina, Sergei Kozlov, "Workshops on photonics and optoinformatics for school students at ITMO University," Proc. SPIE 10452, 14th Conference on Education and Training in Optics and Photonics: ETOP 2017, 104526I (16 August 2017); doi: 10.1117/12.2269954

SPIE Event: 14th Conference on Education and Training in Optics and Photonics, ETOP 2017, 2017, Hangzhou, China 


\title{
Workshops on photonics and optoinformatics for school students at ITMO University
}

\author{
Natalia Andreeva $^{\mathrm{a}}$, Azat Ismagilov ${ }^{\mathrm{a}}$, Tatiana Kuzmina ${ }^{\mathrm{a}}$, Sergei Kozlov ${ }^{\mathrm{a}}$ \\ aTMO University, 197101, Kronverksky, 49, Saint-Petersburg, Russia
}

\begin{abstract}
The program of workshops on photonics and optoinformatics was created at Department of Photonics and Optical Information Technologies in ITMO University by specialists in scientific and educational areas. These workshops are carried out for students of the best schools of Saint-Petersburg specialized in physics and mathematics, such as Gubernatorial Lyceum and Presidential Lyceum, and best schools of Russia. Every year about 500 of school students come to our workshops, including Annual summer educational practice.
\end{abstract}

Keywords: short term educational program, quantum cryptography, femtosecond optics and technologies, terahertz technologies, applied holography, nanomaterials and nanotechnologies.

\section{INTRODUCTION}

The educational program "Optoinformatics in secondary school" was organized in 2003 year under the personal supervision of Head of Department of Photonics and Optical Information Technologies. Initially, this program consisted of three cycles for school students of different age and level of training. The first cycle consisted of acquaintance with optical phenomena, the second cycle covered the basics of laser technology and optical physics and the third cycle was dedicated to the basics of optoinformatics. Over time, the approach to work with students and the program itself changed several times, which eventually led to the development in 2009 of the program of workshops, which is actual to this day.

\section{WORKSHOPS ON PHOTONICS AND OPTOINFORMATICS}

Workshops on photonics and optoinformatics are new and effective form of work with secondary school students. The program of such workshops was developed by scientific staff of Department of Photonics and Optical Information Technologies of ITMO University. Lectures attract attention of school students to the area of activity connected with scientific and technical direction "Photonics and Optoinformatics" and inspire them to study this scientific and technical area. Practical classes give school students practice of working with devices that are used in modern laboratories of Department and demonstrate the possibilities of modern technologies in given area. All workshops are adapted to the level of school student's knowledge. Workshops are carried out on 4 main areas:

"Quantum Informatics": lecture gives information about principles and application of new branch of science devoted to usage of quantum objects for processing and transmitting of information. During practical class each participant has opportunity to send and receive secret message by setup of quantum cryptography and manually compare the result;

"Terahertz optics and Biomedicine": the lecture reviews the principles of generation of terahertz radiation, shows mechanisms of interaction between terahertz radiation and biological objects. During practical class school students take part in workshop on terahertz spectroscopy of biological objects and metamaterials;

"Femtosecond optics and Femtotechnologies": lecture presents the principles of generation of femtosecond pulsed radiation with wide possibilities of its usage. Practical class demonstrates how real setup on the analysis of food products really works;

"Applied holography": lecture gives an overview of holographic method of recording and reconstruction of information and the most perspective applications. In addition, the latest researches in the area of applications of holographic method are discussed, and an overview of existing and emerging materials for holography is given ${ }^{1}$, giving the opportunity not only to assess the physics of the process but also understand the technical difficulties and challenges that exist today in this scientific area. At practical class each participant could record display hologram and take it as a present from laboratory.

Workshops on photonics and optoinformatics are carrying out regularly in the form of short term educational program during one week several times a year.

14th Conference on Education and Training in Optics and Photonics: ETOP 2017, edited by Xu Liu,

Xi-Cheng Zhang, Proc. of SPIE Vol. 10452, 104526I · C 2017 ICO, IEEE, OSA, SPIE

CCC code: $0277-786 \mathrm{X} / 17 / \$ 18 \cdot$ doi: $10.1117 / 12.2269954$

Proc. of SPIE Vol. 10452 104526I-1 


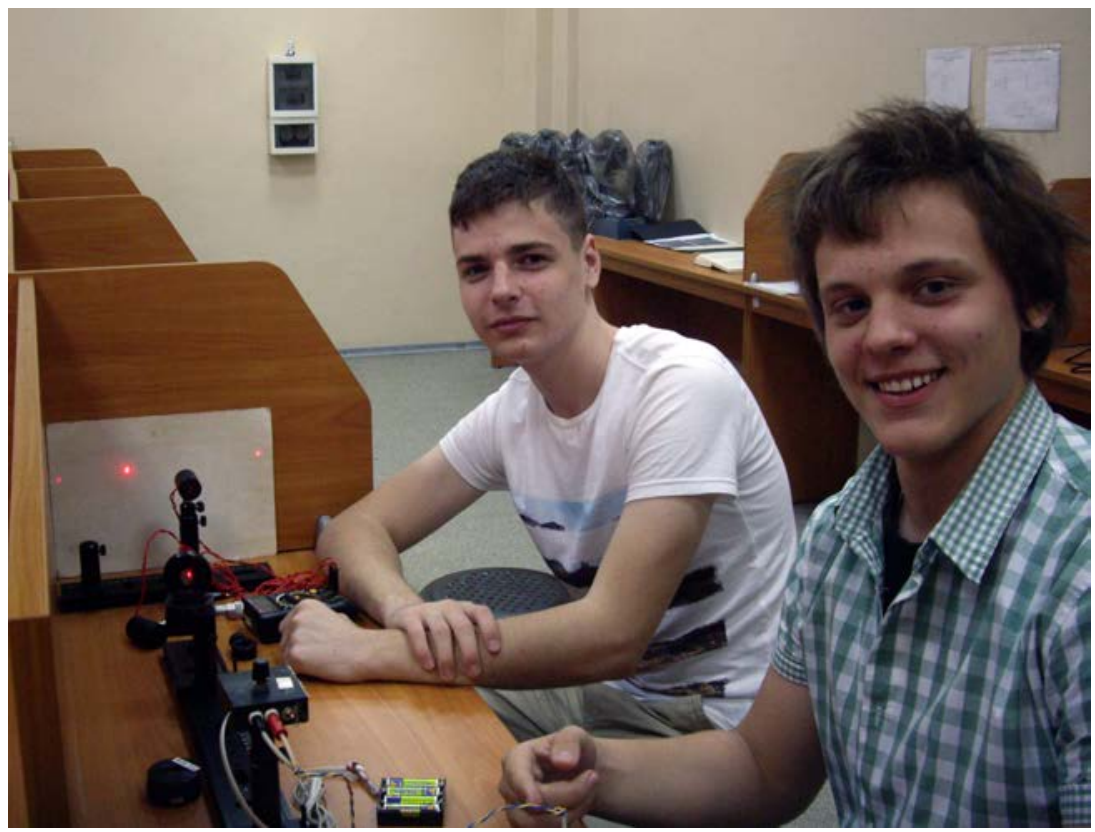

Figure 1. School students from Gubernatorial Lyceum during summer practice in laboratory “Optoinformatics”.

\section{ANNUAL SUMMER EDUCATIONAL PRACTICE}

All these workshops are included into the program of Annual summer educational practice of secondary school students. During this practice, school students can also attend additional workshop "Nanomaterials and nanotechnologies" and see nano-objects that are used in the mathematical apparatus and in the experiments. As example, they can see analyzer of sizes of nanoparticles and stand of digital holographic interferometry, and get ensured that the modern practical physics is able to assess the properties of the object and to carry out measurements even in the nanometer scale. ${ }^{2}$

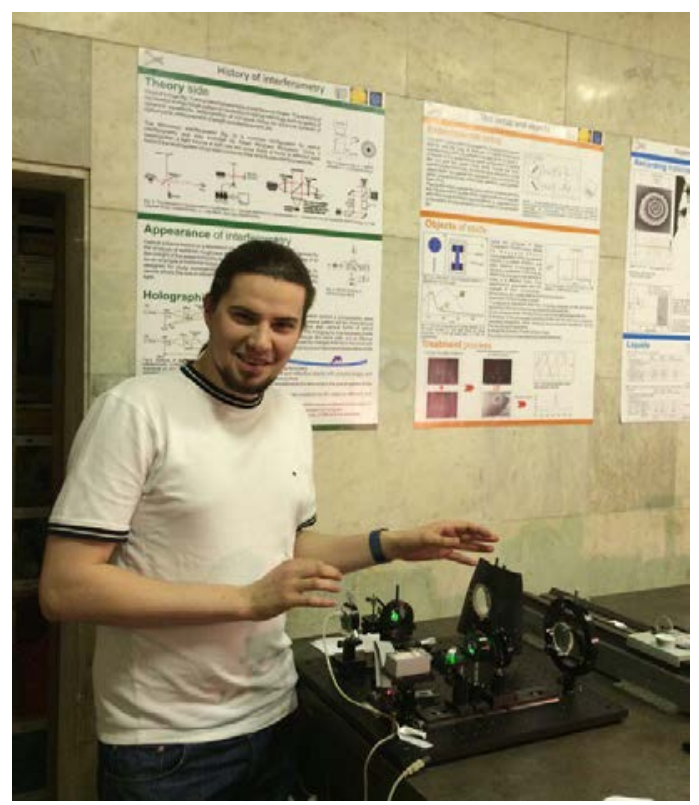

Figure 2. Manukhin Boris, researcher of Department of Photonics and Optical Information Technologies, explain the principles of working of stand of digital holographic interferometry.

This practice is holding annually from 2003 year and among participants of it are students of the best schools of Saint-Petersburg, such as Gubernatorial Lyceum and Presidential Lyceum, and some foreign countries. 


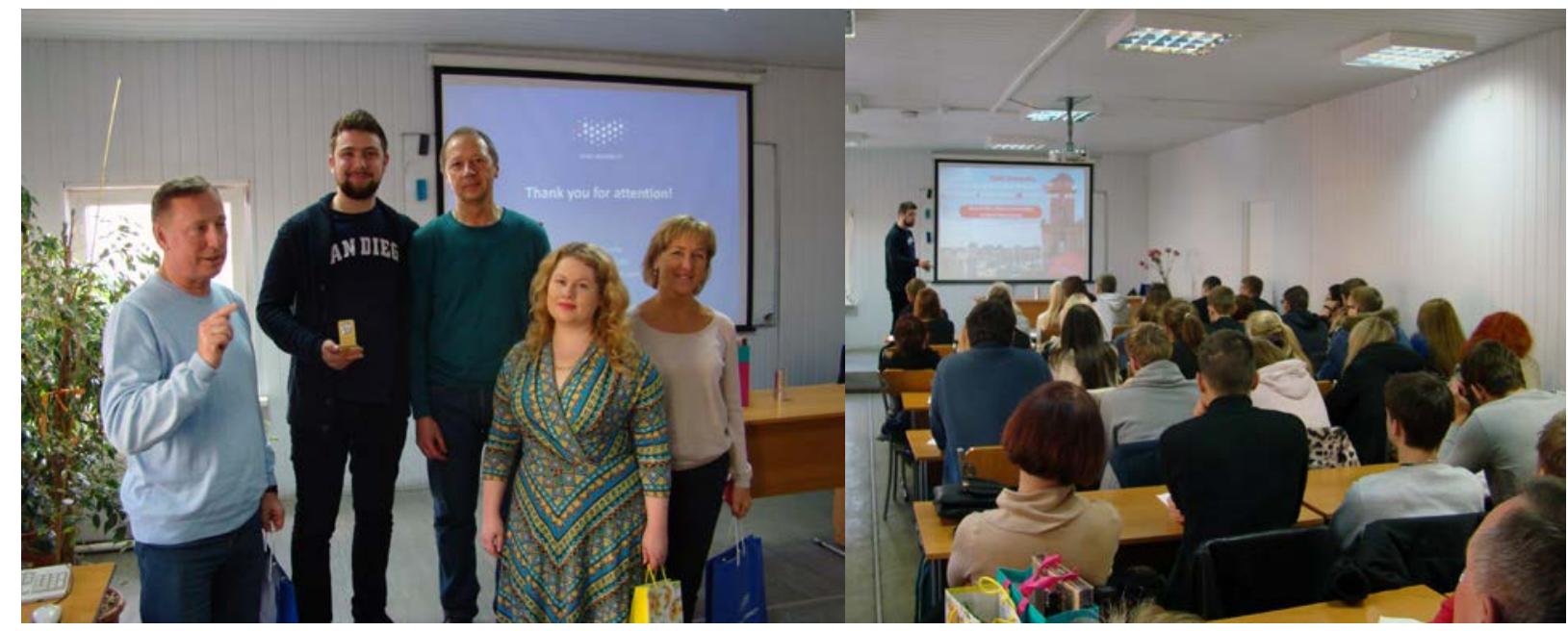

Figure 3. Group of secondary school students from Tallinn, Estonia. Delegation is headed by director and deputy director of Liceum.

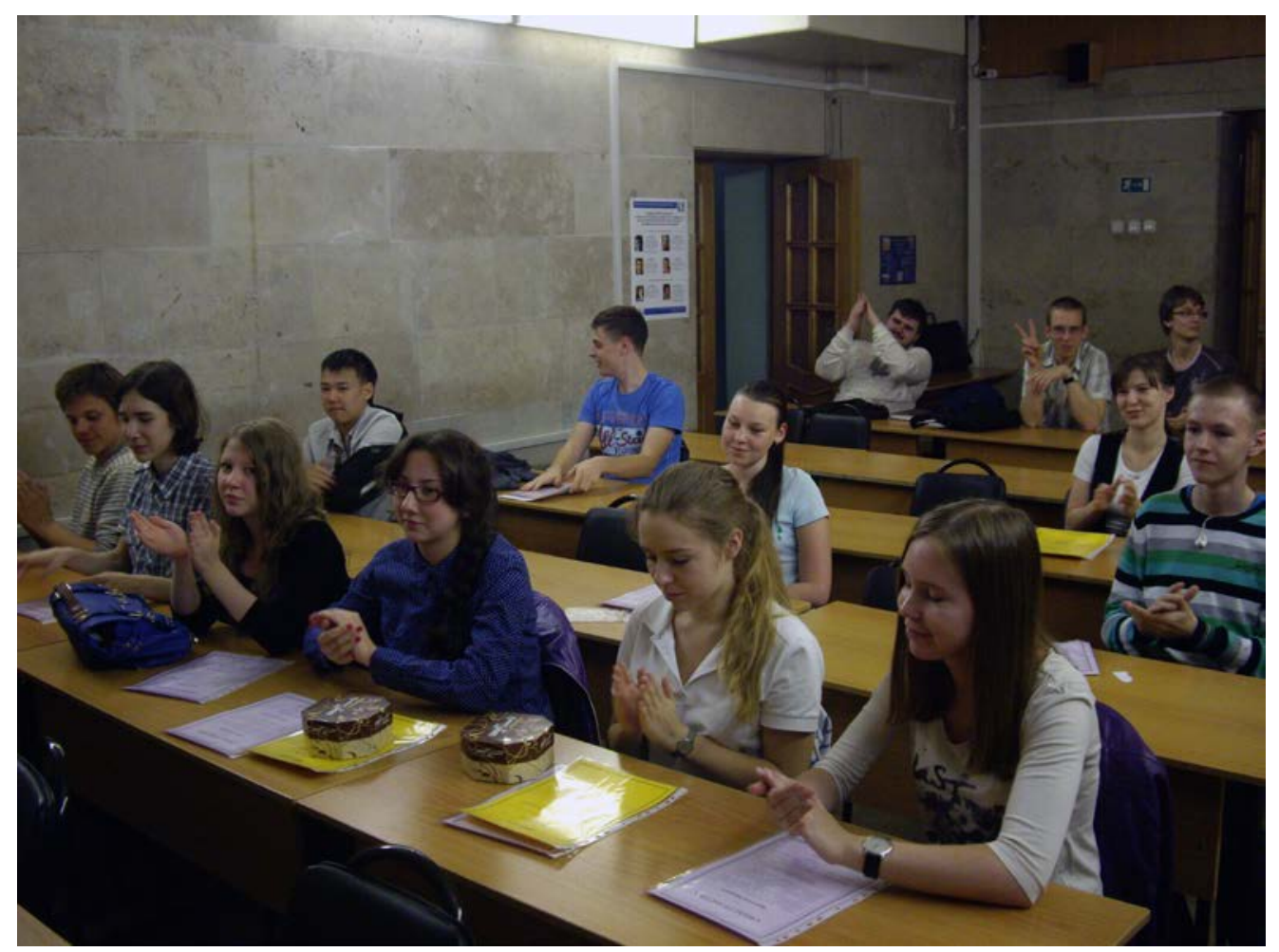

Figure 4. Ceremony of awarding school students by certificates on passage of summer practice.

The results of work with school students were presented on International Conference "Physics in the system of modern education" and on HOPE annual forum: Inspiring young people to study physics, Helsinki, Finland. ${ }^{3}$ The problems of inspiring school students to study physics were also discussed on Meeting of Work Group 3 in Dublin, Ireland. 


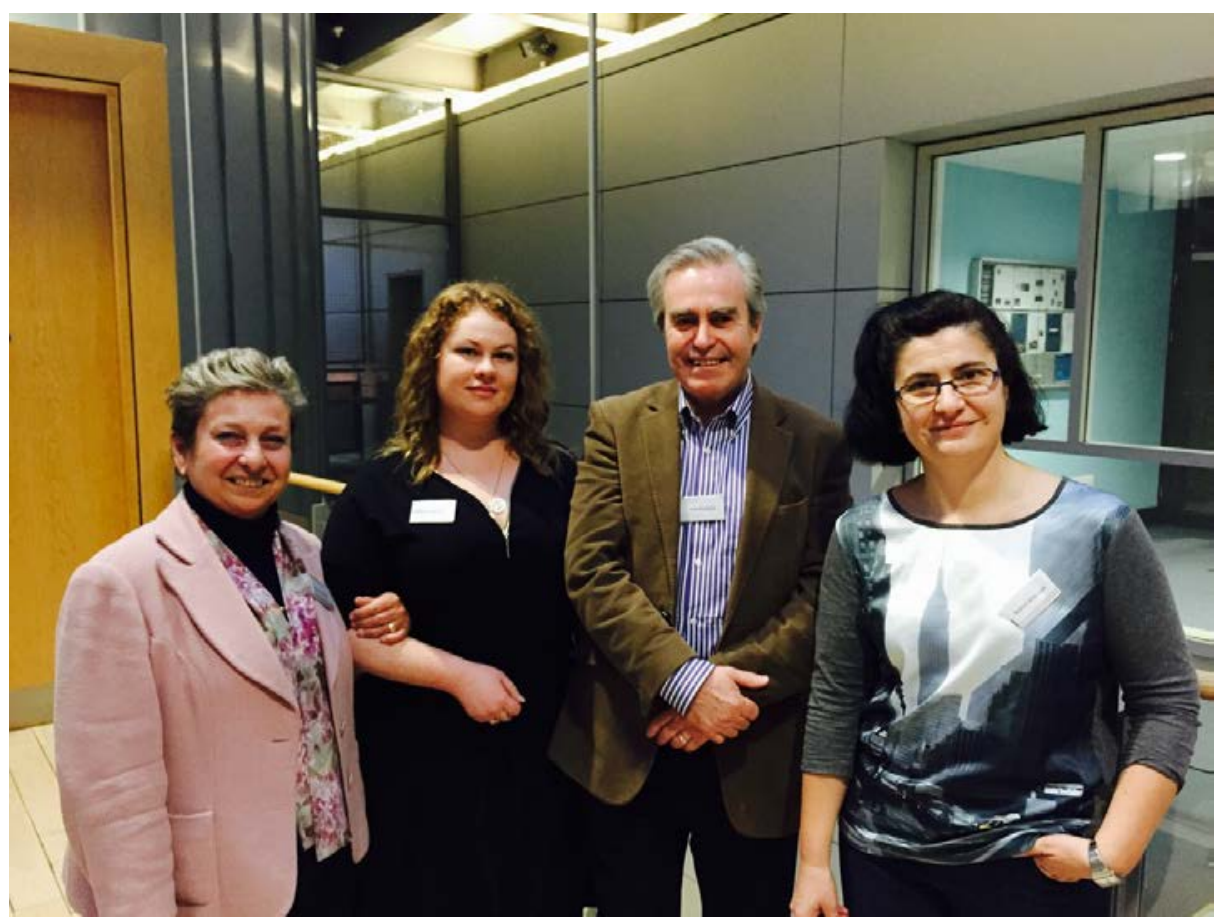

Figure 5. Hope Work Group 3 Meeting, Dublin. Marisa Michelini of Università degli Studi di Udine in Udine, Natalia Andreeva of ITMO University, Saint-Petersburg, Ivan Ruddock of the University of Stratchlyde, Glasgow, Nadine Witkowski of Pierre et Marie Curie University in Paris.

In 2017 Department of Photonics and Optical Information Technologies of ITMO University is getting ready to welcome new school students at Annual summer educational practice.

\section{ACKNOWLEDGMENTS}

Authors are grateful to Dr. Artur Gleim, head of quantum information laboratory, ITMO University, Dr. Anton Tcypkin, head of femtosecond optics and femtotechologies laboratory, ITMO University, Dr. Mikhail Khodzitsky, head of terahertz biomedicine laboratory, ITMO University, Dr. Olga Andreeva, head of scientific group "Optical diagnostics”, ITMO University, Maksim Melnik, researcher of Department of Photonics and Optical Information Technologies, ITMO University. This work was supported by Government of Russian Federation, Grant 074-U01.

\section{REFERENCES}

[1] Andreeva, O. V., Andreeva, N. V. and Kuzmina, T. B., "Plasmonic particles of colloidal silver in highresolution recording media," Optics and Spectroscopy, 122(1), 52-58 (2017).

[2] Andreeva, N. V., Kuzmina, T. B. and Andreeva, O. V., "Research of plasmon resonance in developed holographic photomaterials," Journal of Physics: Conference Series 737(1), (2016).

[3] Andreeva, N. V., Andreeva, O. V., Chivilikhin, S. A., Khodzitskiy, M. K., Tcypkin, A. N., and Kozlov, S. A., "Workshops on photonics and optoinformatics for secondary school students," Hope annual forum 2014 Inspiring young people to study physics, 17, (2014). 